\title{
Study of nutritional status of children attending OPD at a tertiary-care hospi- tal in eastern region of Nepal
}

\author{
RM Rajbandari ${ }^{1}$, O Lewis ${ }^{1}, \mathrm{R}$ Singh $^{2}$, S Smith ${ }^{1}$ \\ ${ }^{1}$ Department of General Practices and Emergency Medicine, BPKIHS, Dharan. \\ ${ }^{2}$ Department of Pediatrics and Adolescent Medicine, BPKIHS, Dharan.
}

\begin{abstract}
Background: Prevalence of malnutrition is high in Nepal. Early intervention improves outcome of children. Objectives: To study the occurrence of the malnutrition in under five children coming to the OPD at BPKIHS and to find out the age group \& sex most severely affected by malnutrition. Methods: A descriptive cross sectional hospital-based study was carried out from 2003-04. 500 children aged 1-5 years were taken as a sample The children needing emergency care were excluded. The Indian Academy of Pediatrics (IAP) and WHO classification were used for grading malnutrition. Results: Total patient were 500 aged $1-5 \mathrm{yrs}$ group. Total malnutrition cases were 124 with a prevalence of $24.8 \%$.Malnutrition was highest in 3-4 years group (33.3\%). Conclusion: It is found that total malnutrition cases were about 24.8\%.A more elaborate and community based study would help to find prevalence of malnutrition in children of Eastern Nepal.
\end{abstract}

Keywords: nutritional status, PEM, affected by malnutrition

\section{Introduction}

The Nutritional status of children indicates the Nutritional profile of a community as a whole. ${ }^{1}$ PEM is on of the major health problems in the developing countries especially in poor countries like Nepal. Preschool children are the age group must vulnerable to malnutrition. ${ }^{2}$ Malnutrition has been seen in children coming to B. P. Koirala Institute of Health Sciences (BPKIHS), Dharan, Nepal. It is more likely to occur among poor people of the Terai (rural areas) regions as well as less educated and poor people of hilly regions. Malnutrition is associated with serious respiratory tract infection, diarrhea, TB etc which is likely to lead to admission of children less than 5 years old to the hospital.

\section{Objectives}

1 To study the occurrence of the malnutrition in under five children coming to the OPD at BPKIHS, Dharan.

Address for correspondence:

Dr.Rajendra Man Rajbandari, Assistant Professor

Department of General Practices and Emergency Medicine, BPKIHS, Dharan

Email: rajendrarajbhandari@ hotmail.com
2. To find out the age group \& sex most severely affected by malnutrition.

\section{Methods}

This is a descriptive cross- sectional study of 1 year period with a sample size of five hundred children.

\section{Inclusion criteria}

Children e" 1 year and d" 5 year attending OPD

\section{Exclusion criteria}

Children who were too agitated \& unwilling for anthropometric measurements were excluded from the study. Those who were very sick requiring Emergency treatment were referred to Emergency. The Indian Academy of Pediatrics (IAP) and WHO classification were used for grading malnutrition.

The results were compared with the NCHS referred (Harvard $50^{\text {th }}$ percentile).

Standard statistical method was used in the analysis of the data with use of MS Excel and Epi-Info software. 


\section{Results}

Occurrence of malnutrition (1-5years): Out of 500 patients aged 1-5 years, the total malnutrition cases were 124 . Hence, the hospital outpatient based, estimated occurrence of malnutrition was $24.8 \%$ in the 1-5 years age group. The distribution is shown in Table.

Table 1: Distribution of malnutrition by Age group and grading
Nutritional status of OPD children at a tertiary-care hospital

\section{According to the WHO criteria}

In my study stunting was $86(17.2 \%)$, wasting $59(11.8 \%)$,wasted and stunted were $5(1.0 \%)$ and total PEM was 150 (30\%).

\section{Discussion}

Nepal is one of the developing countries with extreme poverty. Factors affecting child survival in Nepal may be considered as the outcome of the complex interplay of illiteracy and poverty, which are still dominating the common people of Nepal. ${ }^{3}$

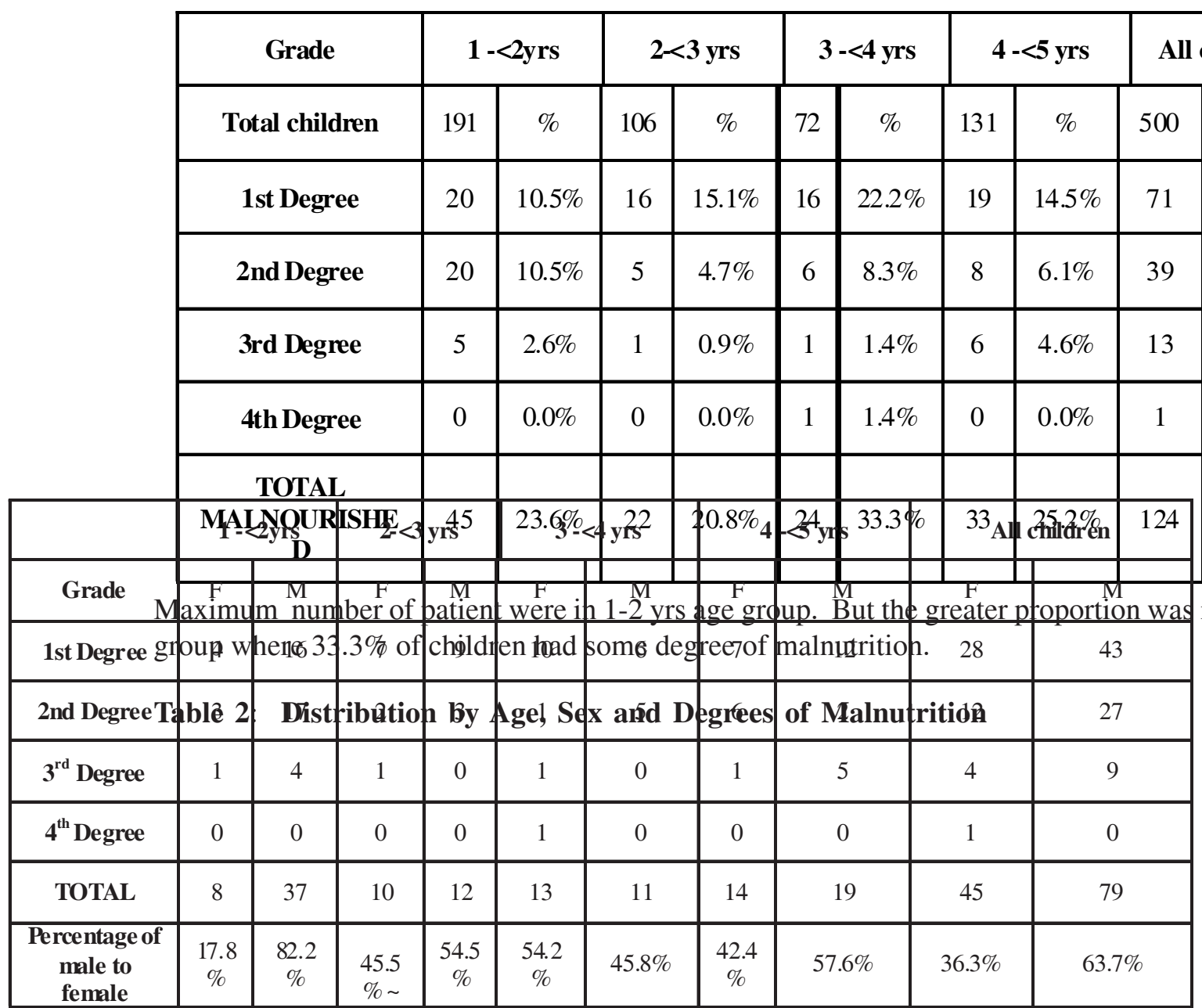

Overall the male to female ratio was about 2: 1 (63.7\% to 36.3\%). Maximum number of patient was observed in $1^{\text {st }}$ degree malnutrition. Maximum number of patient was both in $1^{\text {st }}$ and $2^{\text {nd }}$ degree malnutrition in age group $1-<2$ yrs each with 20, with male 4-5 times higher than females. 
Table 3: Distribution of stunting-height for age

\section{According to Waterloo classification}

Stunting was observed in total 91 patients. Maximum number of stunted 16 each in age group of 1-2 and 4-5 years, but with 12 in age group 3-5 years has highest in percentage ( $16.7 \%$ ).Maximum number of severely stunted children were in 1-2 years age group numbering 15 (7.9\%).

\section{Table 4: Stunting and wasting}

Protein energy malnutrition (PEM) is a worldwide problem with major effects on children's wellbeing. In Nepal and specifically Dharan, existing data shows under nutrition in children to be a significant issue. It is not simply related to poverty but there are many factors involved, such as infections, gender, feeding practices and maternal education. This study aims to study the various degree of PEM and look at some of these factors in the child population attending BPKIHS. BPKIHS is a tertiary care center in eastern Nepal. So not only Nepali but also Indians from the villages and cities bordering Nepal come to this Institute for treatment.

Distribution of malnutrition by age group and grading

In our study a total of 500 children were assessed. Out of 500 patients aged 1-5 years, 124 were found to be malnourished. Hence, the hospital outpatient based estimated prevalence of malnutrition was $24.8 \%$ in the 1-5 years age group. The Maximum number of patients was in the 1-2 year age group with PEM
(23.6\%), but the prevalence was higher in the 3-4 year age group (33\%). In the study of Singh $\mathrm{R}^{3}$ et al at BPKIHS the total PEM was $61(11.7 \%)$. Maximum number of patient was observed in 2-4 years. In the study of Panda $\mathrm{P}^{4}$ et al from India, Punjab the total PEM was $65.3 \%$ amongst under-five children." Bhata ${ }^{5}$ et al in their study from Lalitpur had 104 (86.67\%) PEM children out of 120 studied. PEM was more prevalent in 25 to 36 months of age qroup." In the study of Tada ${ }^{6}$ et al from Thailand, prevalence of PEM was $25.4 \%$ which is similar to our study.

\section{Degrees of malnutrition or grading of malnutrition}

In our study the total of 1 st degree malnourished children were 71 (14.5\%), of which maximum was 16(22.2) in 3-4 years of age group. The total 2 nd degree malnourished children were $39(7.8 \%)$, maximum of which was $20(10.5 \%)$ in 1-2 years of age group. The total 3rd degree malnourished children were 13(2.6\%) in which maximum was in 4-5 years of age group. The total 4 th degree was only $1(0.2 \%)$ in $3-4$ years of 
age group. In the study of Bhata $\mathrm{K}^{5}$ et al, there were $55.8 \%$ with 1 st degree malnutrition." In the study of Singh $\mathrm{R}^{3}$ et al, the maximum number of patient were observed with 2 nd degree malnutrition i.e., 28(45.90\%). 1 In the study of Panda ${ }^{4}$ et al from Punjab (India), the maximum was observed with 1st degree $(35 \%)$ malnutrition.

\section{Distribution by age, sex and degree of malnutrition}

In our study overall male to female ratio was $2: 1$ (63.7\% to 36.3\%). The Maximum number of patients were observed both in first and second degree PEM in 1-2 years age group each with 20 in number, with male $4-5$ times higher than female (17.8\% to $82.2 \%$ ) in the 1-2 years of age group. In the study of $\mathrm{Singh}^{3}$ et al, M:F was 59:40. Maximum number of patients was observed in second degree malnutrition (45.90\%). But it was the 2-4 year age group which had the highest percentage of malnutrition (36.07\%) while in the study of Pand ${ }^{4} \mathrm{a}$ et al, M: F was 1:2. Girls and boys both suffered from second degree malnutrition $(6.4 \%$ $10.7 \%) .{ }^{3}$ In the study of Bhatta ${ }^{5}$ et al, more girls $(62 \%)$ were malnourished than boys (42\%) i.e. M:F ratio was $1: 1.5$. This reversal of the ratio may reflect local values which favour the male child in eastern Nepal and neglect of girl child.

\section{Conclusion}

It was found that total malnourished occurrence was (24.8\%), the greater proportion was in the 3-4 years of age group where $33.3 \%$ of children had some degree of malnutrition.
Maximum number of stunted 16 each in age group of 1-2 and 4-5 years .A more elaborate and community based study would help to find prevalence of malnutrition in children of eastern Nepal.

\section{Reference}

1. Gautam M. Malnutrition in Nepal: A Review, JNMA 1996;VoI.34, NO.118 \& 119:141-151.

2. Grigby DG. Malnutrition. Available on www.emedicine.com. Last updated Dec182003 Accessed on 21.5.05.

3. Singh R, Sarkar G, Shekhar MC, Baral DO. A profile of malnutrition cases at BPKIHS,

JNMA. 1996; 3:254-257

4. Panda P, Prakash R, Benjamin AI, Singh S, Zachariah P. Nutritional and immunization status among under-fives and changes there to over last five years in a Punjab village. Indian J Matern Child Health. 1995 Apr-Jun; 6(2): 54-6.

5. Bhatta K, Mishra S, Gurung GM. Nutritional status of children under five years in social perspective. JAMA. 1998; 37:614-619.

6. Tada Y, Keiwkarnka B, Pancharuniti N, Chamroonsawasdi K. Nutritional status of the preschool children of the Klong Toey slum, Bangkok. Southeast Asian J Trop Med Public Health. 2002 Sep; 33(3):628 